This is a peer-reviewed, accepted author manuscript of the following research article: Marwick, $H_{\text {., }}$ White, E. J., Rutanen, N., Souza Amorim, K., Herold, LKM., \& Karagiannidou, E. (Accepted/In press). Expectations and emotions concerning infant transitions to ECEC: international dialogues with parents and teachers. European Early Childhood Education Research Journal, 28(3).

\title{
Expectations and emotions concerning infant transitions to ECEC: International dialogues with parents and teachers
}

\author{
E.J. White (RMIT, Australia) Jayne.white@rmit.edu.au, N. Rutanen (Department of \\ Education niina.a.rutanen@jyu.fi, University of Jyväskylä, Finland), H. Marwick \\ (Strathclyde University, Scotland) helen.marwick@strath.ac.uk, K. Souza Amorim (Sao \\ Paulo University, Brazil) katiamorim@ffclrp.usp.br, E. Karagiannidou (Strathclyde \\ University) eleni.karagiannidou@strath.ac.uk, \& L.K.M. Herold (University of Arkansas, \\ United States of America)lkherold@uark.edu
}

\begin{abstract}
Although a large body of literature recognises the impact of parent-teacher relationships on infant everyday experiences, less is known about the emotional experience and associated expectations of the adults themselves during earliest transitions. In the context of a multi-site international investigation across five countries - Brazil, Finland, Scotland, New Zealand, and the United States - the present paper seeks to address this gap. This research examines teacher and parent interviews to reveal expectations prior to and after the transition to ECEC, highlighting the associated emotions that arise during this process. Findings show that, irrespective of whether expectations are met, parents universally express insecurities and fears in relation to the transition. Parents are aware of the impact that the various aspects of the ECEC setting have on their child, and acknowledge difficulty in relinquishing control of the care of their child. Despite these concerns, parents consistently articulate their strong trust in the institution and the professional expertise of the staff. Correspondingly, teachers are keenly aware of the importance of their role in supporting families, and hold certain expectations for how the transition experience will play out accordingly. Regardless of country of context, the study shows that clear communication surrounding both centre and parental expectations establishes high levels of trust and ameliorates anxiety. Teacher-parent dialogues concerning routines, preferences, and anticipations are seen as pivotal in supporting a positive transition for all.
\end{abstract}

Keywords: Transition, Infant, Parent, Infant teacher, ECEC teacher, Expectation, Emotions Pedagogy

\section{Introduction}

Now that infants all over the world are increasingly entering into early childhood education and care contexts (OECD 2017; Dalli \& White, 2017), a need arises to understand their social and emotional experience in this new locale. The significant social changes that occur during early transitions call for investigation of the contexts in which the infant is cared for outside of the home - often for long hours and under the supervision of non-familial adults. To date, very little is known about this experience and its impact, despite the fact that a large body of psychological literature indicates negative effects of infant daycare attendance, particularly on a child's long-term social and emotional development (Friedman \& Boyle, 2008). A small volume of recent studies question this inherent harm perspective, with some pointing to possibly positive aspects of ECEC participation (see review Melhuish et al., 2015). For 
This is a peer-reviewed, accepted author manuscript of the following research article: Marwick, H., White, E. J., Rutanen, N., Souza Amorim, K., Herold, LKM., \& Karagiannidou, E. (Accepted/In press). Expectations and emotions concerning infant transitions to ECEC: international dialogues with parents and teachers. European Early Childhood Education Research Journal, 28(3).

example, Herba et al. (2013) report on a Canadian longitudinal study where negative emotional issues in infants (including withdrawal and separation anxiety) were found to be greatly ameliorated by ECEC attendance. This modifying role of ECEC is also discussed by Lee et al. (2006) and Giles et al. (2011) but only in relation to 'at-risk' infants and their mothers who reported high levels of depression. Less still is known about infant experiences during earliest transitions to ECEC.

The few extant studies on first transition from home care to ECEC setting tend to highlight the emotional experience of the infants themselves - in isolation of the emotions of their relational others. For instance, Klette and Killen (2018) examined one-year-old infant reactions during ECEC arrivals and departures one month after their initial transition. Their psychoanalytical analysis revealed levels of distress consistent with phases of separation anxiety, emphasising the importance of stable, sensitive and empathic carers. They argue that education, training and language skills to support these qualities are necessary for effective infant transitions, a point reinforced by Barros et al. (2017) in Portugal. These findings are replicated in a recent study across five countries by Pirskanen et al. (2019) who found similarities in the intensity of the emotional experience of transitions for children aged 5 to 7 moving from preschool to first grade in school. The authors argue for the importance of emotional support for children in managing these intense emotions. However, they do not take into account the expectations or emotions of parents or teachers in these transitions.

Traum and Moran (2016) provide one of few exceptions to this lacuna in a US investigation of parents' and teachers' beliefs and values during ECEC drop off and pick up. They highlight the complex interplay of values, concerns, regrets, and desires both parties placed on the emotional well-being of infants during the transition. They conclude that the outward appearance of both teachers and parents during daily transitions do not necessarily convey the full emotional impact experienced by adults. Monk and Hall (2017) similarly suggest that early transitions to ECEC can be highly stressful for infants and caregivers. These authors illustrate the complex cultural practices that affect the transition experience when mothers return to work in the first 12 months after the baby's birth. They posit three interconnected themes that influence the emotions experienced by mothers as they negotiate the significant tensions between home, work, and ECEC service: 1) societal, cultural, and institutional expectations of mothers, 2) personal choices perceived as available, and 3) interpersonal tensions arising when expectations or choices conflict with practices.

Clearly, these earliest transitions are often highly emotional events for families; yet very little is known about adults' emotions and their impact on infant's well-being in ECEC. We suspect that this is especially relevant when parents/mothers feel that they must return to work (OECD 2017). The situation is further exacerbated by a pervasive scientific legacy (e.g., Bowlby) and societal/cultural beliefs that group-based ECEC may be harmful for infants. The associated expectations of parents and teachers in ECEC can be various and potentially mismatched (Goouch \& Powell, 2017); while emotional responses for parents diverse (Monk \& Hall, 2017). Examinations of both perspectives are needed to understand how expectations affect the emotional experience for all concerned.

\section{Introducing the study}

The present study sought to understand the emotional experience of transition and its relationship to parents and teachers expectations across five countries, as part of a wider 
This is a peer-reviewed, accepted author manuscript of the following research article: Marwick, $H_{\text {., }}$ White, E. J., Rutanen, N., Souza Amorim, K., Herold, LKM., \& Karagiannidou, E. (Accepted/In press). Expectations and emotions concerning infant transitions to ECEC: international dialogues with parents and teachers. European Early Childhood Education Research Journal, 28(3).

international collaboration investigating the social emotional experience of transition to and within early childhood education and care (ISSEET - International Study of Social Emotional Early Transitions). The extent to which expectations before and immediately following the first transition to ECEC shaped emotions on the part of parents and teachers are the focus of this paper.

\section{Methodology}

Dialogic methodology (Bakhtin, 1986) was used to explore emotion as a living phenomenon that not only exists between people, but is influenced by the event itself - in this case, through the expectations that are brought to the transition. Bakhtin prescribes this approach to research as both "thought striving to embrace the world and thought experiencing itself in the world (as part of it)" (p.162). Given our emphasis we drew specifically on Beech's (2010) associated notion of dialogic liminality to position the event of transition as "...a more longitudinal experience of ambiguity and in-between-ness within a changeful context" to orient our investigation. This event of "between-ness" (Beech 2010; Traum \& Moran 2016) plays out in dynamic emotional interplays over time, within diverse contexts (home, work, and ECEC) and through dialogues between parents and teachers. We interpret these through what Beech calls 'inside-out' (in our case teacher to family) and 'outside-in' (for us, family to teacher) dialogues concerning the expectations of both for the infant during transition. These complex interplays and shifting boundaries impact the transition for all parties - not least the infants themselves.

The present paper therefore sets out to understand the emotional experience of infants' transitions to ECEC through the articulated expectations and emotions of parents and teachers immediately before the infant starts attending ECEC and in the months following the event. Emphasis is correspondingly placed on the ambiguous, unstable experiences and processes that are experienced emotionally and socially, triggered by certain routines, events and practices performed within social and cultural spaces and characterised by change.

We ask:

"What is the relationship between parents' and teachers' expectations and the emotional event of transition during the first few weeks of infant transition to ECEC?"

Method

The present paper is part of an ongoing longitudinal "International Social and Emotional Experiences in Early Transitions" (ISEET) project that sets out to understand the transition experience from infancy to school through regular interviews, observations and video capture across key transition moments over time. For the purposes of this paper data is drawn from the first transition experience only. Expectations and emotions were excavated in two sets of parent and teacher semi-structured 1-1 interviews as part of a much wider corpus of interviews that took place over time. The first interview aimed to generate findings about expectations and emotions of parents and teachers in relation to the transition, to their own emotional reactions, and to infant's emotional and social experiences. In the subsequent interview, parents and teachers were asked to reflect on the first month of the transition and indicate how they felt, what they noticed in the infant's emotional and social experience, and any changes and 
This is a peer-reviewed, accepted author manuscript of the following research article: Marwick, $H_{\text {., }}$ White, E. J., Rutanen, N., Souza Amorim, K., Herold, LKM., \& Karagiannidou, E. (Accepted/In press). Expectations and emotions concerning infant transitions to ECEC: international dialogues with parents and teachers. European Early Childhood Education Research Journal, 28(3).

challenges which have occurred. A total of 10 parent interviews and 12 teacher interviews across five countries form the basis of the analysis presented here.

Ethical approval for the projects were granted by the ethics committees of each participating university. There are diverse constraints for the data use and sharing, and these have influenced the methodological decisions for the overall project. The ethical tensions and challenges related to the project are discussed elsewhere in detail (see Rutanen, Amorim, Marwick, \& White, 2018). Follow up interviews and well-established relationships with parents and teachers were a priority for the researchers concerning the emotional nature of these experiences.

Analysis

Research teams across each country analysed country-specific data before bringing their findings into joint discussion. The unit of analysis was found in the identified intersections between expectations and emotions across interview periods and which highlight the complex interrelationship between both during earliest transitions:

i) Expectations: anticipation of something in terms of the infant starting ECEC - positive (e.g. 'high expectations'), negative, or ambivalent;

ii) Emotions: expressed hopes, fears, anxieties that were linked to expectations - either anticipated, met, negotiated or unfulfilled.

\section{Participants}

ECEC centres in Brazil, Finland, New Zealand, Scotland and the United States catering for infants were selected for this study. The age of the infants at point of transition ranged from 6 months to 1.5 years. The reason for attendance was overwhelmingly due to the mother returning to or hoping to start work. The infant's attendance ranged from 8-9.5 hours a day, 4 or 5 days a week, (NZ, Brazil, Finland, US) to few hours in 2-3 days a week (Scotland). Settings included public/community (Scotland), private (Finland, US \& NZ), and private without profit (Brazil). Policies concerning the desirable age of entry to ECEC vary across these countries and range from birth to one year. These ages accord with policies concerning parental leave which provide less incentives for some parents than for others. A fuller analysis of these and related policies is discussed elsewhere (see Gradovski et al, 2019), suffice to say that Finland parents were offered more parental leave than other countries, and infants were older upon entry to ECEC as a consequence.

This paper focuses on seven parent interviews and seven teacher interviews (one of each in Finland, USA and Scotland; two of each for NZ (one of European ethnicity and the other indigenous Maori) and Brazil to reflect bicultural priorities for their countries) who were associated with the transitioning infants. Parents interviews involved 6 mothers and two fathers Teachers were all female. The professional background of the teachers varies, ranging from Pedagogy Faculty courses in Brazil to Master's level degree in Scotland, although we use the inclusive term "teachers", to refer to all ECEC staff who were interviewed, regardless of their qualification. In doing so we do not in any way diminish the professional nature of teachers work, but rather reflect the existing status of what constitutes a 'teacher' for each of the countries involved.

A total of 14 interviews were analysed for the section that follows. 
This is a peer-reviewed, accepted author manuscript of the following research article: Marwick, $H_{\text {., }}$ White, E. J., Rutanen, N., Souza Amorim, K., Herold, LKM., \& Karagiannidou, E. (Accepted/In press). Expectations and emotions concerning infant transitions to ECEC: international dialogues with parents and teachers. European Early Childhood Education Research Journal, 28(3).

Results

\section{Outside-in emotions concerning infant transition}

In every case across all five countries, the start of ECEC attendance at infancy was related to the mother's return to work - regardless of what policies existed to support or thwart their ability to stay at home. However, the way parents felt about this event differed markedly. The timing of the transition was an important aspect in structuring the emotional aspects of the process. If the timing and pace was mostly out their control, parents felt more insecure about the changes. A Scottish mother commented that her return to work had been delayed although the infant's transition into childcare had already been arranged, and that this took the "pressure" off for these first weeks of transition, as there were no work obligations to contend with. In other families, the transition had been planned for many months. In the Brazilian case, there was a feeling of relief as the (single) mother had already returned to work without stable daily care for the child. Despite sadness linked to leaving the child the lack of established consistent care systems in her life meant that ECEC was seen as a good solution. As for all parents interviewed, the transition marked the end of an era in the life of the parent.

Whatever their reason, all parents interviewed expressed some anxieties concerning the transition. These were greatly exacerbated when parents perceived they had little or no choice due to economic pressures. Levels of anxiety appeared to be greater for these first time parents who - although they anticipated major changes for them and their relationship with their infant - were uncertain of the magnitude of change. A Scottish mother explained, "we don't have any family here who regularly look after child, so I think her being with someone other than us is still a big deal, like it's still not like routine". Other parents were reassured that their infant would do well based on previous experiences, even though they recognized the challenges ahead. A US father stated "She's the third child. I have real confidence in the center". A NZ parent, with three children in the same ECEC centre joyfully described an experience of "family: "how cool is it that you get to come and hang out with your [centre] family all day and then you go home and hang out with your family, I love it".

Regardless of their choices for placing their infant in ECEC, all parents felt that this event placed a punctuation mark on their ability to spend time at home with the infant and was tinged with sadness accordingly. In the words of a Finnish mother, there was a "feeling of blue" that the baby-time was over. Despite their fears, parents consistently articulated a vehement belief that "all would be well in the long run". Necessary adjustments for this to occur needed to take into account the priorities of parents as well as the centre. These were often associated with practical issues such as bottle feeding, sleep and routines that were negotiated with the centre. Consistency in routine between home and ECEC centre played an especially important role in how parents felt about the transition. A Finnish mother decided to introduce some similarities to their everyday life at home that responded to the assumed routines at ECEC centre to support their infants' transition. In contrast, a NZ parent held high expectations that her preferences and practices from home would be upheld and was upset to discover that her infant's sleep routines had been altered at the centre. Either way - matching of routines across sites was seen as important for effective transitions to occur. 
This is a peer-reviewed, accepted author manuscript of the following research article: Marwick, $H_{\text {., }}$ White, E. J., Rutanen, N., Souza Amorim, K., Herold, LKM., \& Karagiannidou, E. (Accepted/In press). Expectations and emotions concerning infant transitions to ECEC: international dialogues with parents and teachers. European Early Childhood Education Research Journal, 28(3).

Outside-in expectations

Notwithstanding feelings of sadness, parents held few expectations of the centre beyond their relationship with teachers. They articulated a belief that their infant would be well cared for conveying trust in the ability and professionalism of teachers. A NZ 'first time' parent said of the key teacher working with her infant: "I look to her for knowing what to do." Central to the parent's emotional experience was effective communication with the teachers, and this was closely linked to expectations being met. In many cases, parents openly sought advice concerning what to do during the transition process and expressed their hope that teachers would always be honest in communications concerning their infant, including when the infant was unhappy. A US mother reflected on advice she received from staff: "...they were really strict about saying goodbye, so he knows you're leaving and doesn't panic". A Scottish parent highlighted her emotional reaction to teacher comments, recognising her acute sensitivities to what was said about her infant:

"I think it's just from all these things the learning is that I think I never realised all these tiny, tiny little things and how people say something to you, how emotional all these issues are and like well-meant comments can go that way, or flippant comments or... and there's no way of always saying the right thing'

Across all families interviewed, the ECEC setting was constructed as a new social environment, presenting both novel relations and experiences which, though outside their influence, parents felt would benefit their infant. A Scottish mother reflected, "....we feel that child is totally safe, loved and well looked after, so we don't have concerns about that at all. I think a lot of it is just ... the process of letting go, and accepting that other people will see her a bit differently, or she might be another person with different people". Overall, this opening up to the social world through peer-based learning, negotiating with others' needs, and fitting in with routines, was perceived as important and beneficial for their infant's learning. As a consequence - regardless of which country - parents believed it was their duty to "put on a brave face" so that their infant could benefit.

Inside-out emotions

Teachers in each country were highly aware of their role in supporting parents through transition in what they regarded as an emotionally challenging process for infants. Their dialogues correspondingly focussed much more around the emotions of the infant than the parent. For a teacher in Brazil, crying was seen as a necessary form of communication:

"Infants cry, always. It is their way of expressing. And they will cry as they will be in a place they are not used to, in which they will be apart from their mothers. Thus, is it obvious that they will cry. Some babies cry more, others less. But with our care, they will get to be comforted, fed, caressed. They will have all they need and gradually they will get to be tranquil."

For other teachers, crying was regarded with a degree of ambivalence due to their deeply held beliefs concerning temperament. A Finnish teacher explained that some infants would cry for long periods while others did not - being like "fish in water" from the outset. Considering the infant's emotions as arising from personal characteristics or temperament alone, as opposed to an interaction between the child and the environmental context, sometimes led to conflicting 
This is a peer-reviewed, accepted author manuscript of the following research article: Marwick, H., White, E. J., Rutanen, N., Souza Amorim, K., Herold, LKM., \& Karagiannidou, E. (Accepted/In press). Expectations and emotions concerning infant transitions to ECEC: international dialogues with parents and teachers. European Early Childhood Education Research Journal, 28(3).

interpretations between parents and staff of the child's emotional state. One Scottish mother reported that the childcare centre considered her child's initially limited expressed pleasure to reflect the temperament of the child, and therefore as something which should not be altered. This contrasted with the perspective of the mother, who knew her child as a happy and positive child outside the centre setting.

Other teachers wanted to see a shift from infants crying at all cost, and sought to avoid this by ensuring that they could provide 1-1 attention during the earliest days of transition. One NZ teacher talked at length about the infant as "grieving" and "being brave," which she saw as emotionally harrowing for herself and the infant alike. At the same time, she saw it as an opportunity to develop a primary attachment with the child, with the teacher providing understanding and availability within an attuned and reassuring secure relationship, which she viewed as central to her pedagogy. Similarly, a US teacher spoke at length of the attachment that formed after a rough beginning in which the child refused bottles for several weeks. She cited as evidence the fact that the child would become upset every time her teachers left the room, and noted that "even when she's happy, she kind of looks to us for approval - kind of like she would a parent."

Regardless of their attitudes towards the infants' emotional experience, all teachers invested significant time in building such relationships with parents as an investment in the infant's well-being. As a NZ teacher explains:

"... the more positive parents feel about something like that then the more positive a child is going to feel about it. So I think children are all about sensing energy and fear, so if their parents are being really positive about bringing them here on that first day and dropping them off, and show their confidence in me to look after their child, then it's going to go more smoothly for the child."

Due to their understanding of parent anxieties combined with their own priorities for the infant's well-being in the centre, teachers held a series of expectations for families that were typically expressed in their settling-in policies and/or practices. The settling in period in Scotland, for example, involved a month of visits prior to starting at the centre, as well as a further settling in period following the formal start. At times, these had to be negotiated between the two settings requiring skilful negotiation on the part of teachers. A teacher from Finland explained: "I know it can be hard to leave their most precious thing with someone that they don't know very well - making sure that they can trust me".

\section{Inside-out expectations}

Across all contexts, teachers held clear and consistent expectations of parents concerning the transition experience. In NZ and Scotland, these were articulated through formal transition policies and practices expressing detailed expectations and aspirations for the process, including how responsibilities would be shared to support the child in transitioning and the role of the teacher. Even in the absence of these, across all sites dialogues with parents about their expectations concerning feeding, bottles, and sleep were seen by teachers as important sources of emotional support during transition. Whether they took place during settling-in visits in either the home (in Finland or in the case of Scotland where home visits leading up to transition were a standard practice) or, more typically, in the centre, teachers consistently articulated the 
This is a peer-reviewed, accepted author manuscript of the following research article: Marwick, $\mathrm{H}$., White, E. J., Rutanen, N., Souza Amorim, K., Herold, LKM., \& Karagiannidou, E. (Accepted/In press). Expectations and emotions concerning infant transitions to ECEC: international dialogues with parents and teachers. European Early Childhood Education Research Journal, 28(3).

importance of visits in providing a foundation for the parent-teacher relationship that was to develop. A Scottish teacher explains the value of home visits:

"I think it really helps with all the settling visits, they're so, so important and the home visit is a big, a big thing, I think that really helps to build the relationship within the family. I personally learn so much from them, and I think once the home visit has happened, I think there's sort of this feeling of relaxing, among the whole, within the whole family, and me".

Visits were, however, not always possible due to organizational challenges. In Brazil, for example, a visit could not happen due to organizational complexity. This created dissonance among parents and teachers, as expectations could not be reconciled and disappointments arose as a consequence. Similarly, a US family were on vacation during the scheduled visits. Their infant's extended bottle refusal, which may have been influenced by this lack of prior connection, was described by her teacher as "very stressful" for everyone involved.

Regardless of their policies and practices, teachers across all sites articulated expectations that a 1-1 relationship with the infant was necessary during the early phases of transition. They felt that the extent to which such exclusive attention could be given was constrained by ratios and group size, as well as the timings of the transition. For example, in NZ, Scotland and Brazil the children transitioned at an individualised time, whereas in Finland and the US they began with a group of peers, without teacher agency in the timing. In New Zealand, Finland and Scotland, these processes were linked to formal or informal Key Teacher practices, where a particular person is assigned responsibility for attending the family and the child both before and during the transition (White et al., 2018). For a NZ teacher a Key Teacher arrangement was her aspiration, although not always her reality due to constraints concerning ratios and high numbers of infants transitioning at the same time: "it's my job to be here to support her, that she would come to me".

While developing these strong relationships during the earliest days of transition, by the end of one month a NZ teacher reported the feeling that the infant and she might be "too attached" - highlighting her desire for the infant to extend her emotional network to other teachers. While forming a secure attachment with a child is of key importance in supporting emotional wellbeing (Bowlby, 1969), the consistent availability of a specific key worker may not be possible within the setting (Gallagher and Tait, 2018) - yet for New Zealand teachers it was identified and practiced as a real priority, despite the fact that it was not mandated in policy (White et al, 2018). In Brazil and Finland, teachers emphasized the importance of infant relationships with all the teachers in the centre as a necessity arising from different shifts. However, teachers in Brazil and NZ described tensions when the infant selected a different adult that the one who had been 'assigned' from the outset. Conversely, a teacher in Finland was hesitant to describe any such "tool box for supporting transitions", emphasizing the diverse preference of families in such matters. Clearly, there are very different views across sites concerning the nature of these attachments during transition

\section{Conclusions}

Our findings portray a complex web of interactions leading up to and including the early days for infant transitions which are laden with expectations, both met and unmet, and which play a significant role in orienting the emotions experienced during the transition event. Where 
This is a peer-reviewed, accepted author manuscript of the following research article: Marwick, H., White, E. J., Rutanen, N., Souza Amorim, K., Herold, LKM., \& Karagiannidou, E. (Accepted/In press). Expectations and emotions concerning infant transitions to ECEC: international dialogues with parents and teachers. European Early Childhood Education Research Journal, 28(3).

greater cohesion was found concerning what to expect and how those expectations could be met, the emotional event of transition emerged as a more positive experience for all. Similarly, where the transition was perceived more positively, expectations concerning its outcome and processes were aligned. Expectations were not necessarily shared between parents and teachers across cultural contexts, but when they were aligned it seemed that this was more a result of prior encounters with older children.

Emotions also oriented expectations. Earliest transitions were a highly emotional event for families and teachers alike, linked to perceived personal choices available to families and mediated by experience, beliefs and attitudes. By association prior knowledge and experience are important in forming expectations, as in the absence of those, expectations are easily guided by stereotypical beliefs about categories such as profession, as Kunda and Sherman-Williams (1993) note. Our findings further suggest that stereotypical views of infants - by teachers - are alive and well in the discourse that orients their experience. Emotions are deeply influenced by both met and unmet expectations in relation to actual practices accordingly. Emotions and expectations concerning the transition and its aftermath mutually influence each other in a complex relationship that takes place in between 'inside out' and 'outside in' dialogues regardless of ECEC context it seems. The extent to which teachers see crying as an inevitable aspect of transition, or an emotion to be avoided at all cost appears to orient some of the pedagogies that take place during these events.

Parents and teachers alike brought significant expectation to the preparations surrounding transition. These were largely associated with centre practices that held certain views concerning the infant and their temperament, as well as those that correspondingly supported parents' preferences for their infant's care, and facilitated consistent caregiving practices across both settings. In particular, dialogues between parents and teachers across all countries were seen as an important source of comfort and clarity when they worked well. They took place during home- or centre-based visits prior to transition and also in the dialogues during transition. Expectations and emotions were able to be more aligned as a consequence - in terms of the actual familiarity of the parents and teachers to each other and to the practical aspects of the transition, in consideration of centre priorities. Where alignment was not possible, dialogues became even more important for parents who, in such cases, experienced deep emotional grief and feelings of loss at having their priorities upheld in the upbringing of their child,

When expectations could not be met - for teachers and parents alike - significant emotional anguish was experienced. When teacher aspirations for high quality relationships and slow settling in processes were constrained, emotional turmoil was evident. Parental hopes and dreams for consistent caregiving practices were diminished when their preferences were not upheld and they did not understand why. In all cases, these levels of emotional distress were ameliorated by dialogues across inside out and outside in spaces. A key point arose from the interviews in this regard concerning the idea that "if things are good for the parent, they will also be good for the infant", reinforcing the value and importance of teachers spending time with families during the earliest transition experience. The amount of time required to ensure that parent-teacher dialogues about their expectations and the negotiations that need to take place to ensure all perspectives are heard has been understated in infant pedagogy, and warrants further investigation.

These results especially emphasise the importance of early dialogues between parents and teachers in order to create more positive experiences navigating earliest transition to ECEC for 
This is a peer-reviewed, accepted author manuscript of the following research article: Marwick, $H_{\text {., }}$ White, E. J., Rutanen, N., Souza Amorim, K., Herold, LKM., \& Karagiannidou, E. (Accepted/In press). Expectations and emotions concerning infant transitions to ECEC: international dialogues with parents and teachers. European Early Childhood Education Research Journal, 28(3).

infants. The relationship between teacher and parent is of vital importance to the process regardless of culture or ethnicity - yet there is very little literature supporting teachers to do this well during these early transitions. Parent-teacher relationships prior to, during, and after earliest days are crucial in building trust in the relationships. Whether or not primary caregiver systems were in place these results suggest that when parents have prior knowledge concerning what to expect based on effective dialogues, transitions can be easier. In particular, previous contact and preparation in the form of visits to the centre, and especially home visits, helped parents build clearer expectations about both the teachers and their own roles, as did the associated sharing of practices and routines. These results underscore the importance of teacher-parent-child visits and dialogues prior to the infant starting ECEC, as these enable all parties to build rapport. Similarly, the earliest days call for a more intense and intimate relationship-building process - a need that often goes unrecognised in curriculum, pedagogy or policy. This is particularly important for first time parents and, especially, families who do not have other support networks in place.

This study has only begun to unravel some of the complexities of these emotions during the very specific period of transition to ECEC for infants across several different countries. Importantly, these emotions and the way they are interpreted play a significant role in the transition event, dictating certain responses on the part of families, ECEC services, and teachers. Only by considering the interrelations of all aspects of transitions to ECEC and the interpretations and perspectives of all involved is it possible to comprehend the complex aspects of this unique process. Given the fact that these families felt they had little choice in placing their infant in ECEC at an early age due to economic pressures, there is an associated accountability to governments to ensure the experience is positive for everyone, ultimately, and by association, the infants themselves.

\section{Acknowledgements}

The authors wish to acknowledge the support of their respective University institutions in the funding of this project. Also University of Waikato, NZ and the Cognition Trust NZ who funded the NZ data generation during these early phases of the project. The subproject in Finland was supported by the Academy of Finland (project number to be added after review). Brazil was supported by FAPESP (Fundação de Amparo à Pesquisa do Estado de São Paulo

\section{References}

Bakhtin, M. M. (1986). Speech genres \& other late essays (No. 8; V. W. McGee, Trans.). Austin, Tx: University of Texas.

Barros, S., Cadima, J., Pinto, A.I., Bruant, D.M., Pessanha, C. \& Coelho, V. (2017). The quality of caregiver-child interactions in infant classrooms in Portugal: the role of caregiver education. Research Papers in Education, 33(4), 427-451. https://dx.doi.org/10.1080/02671522.2017.1353676

Beech, N. (2010). Liminality and the process of identity reconstruction. Human Relations, 64(2), 285-302. http://hum.sagepub.com/content/early/2010/09/16/0018726710371235.full.pdf+html 
This is a peer-reviewed, accepted author manuscript of the following research article: Marwick, $H_{\text {., }}$ White, E. J., Rutanen, N., Souza Amorim, K., Herold, LKM., \& Karagiannidou, E. (Accepted/In press). Expectations and emotions concerning infant transitions to ECEC: international dialogues with parents and teachers. European Early Childhood Education Research Journal, 28(3).

Bowlby, J. (1969) Attachment and Loss. Vol 1: Attachment. London: Hogarth Press.

Dalli, C. \& White, E.J. (2017). Policy and pedagogy for birth-to-three year olds In E.J. White \& C. Dalli (Eds.), Under three year-olds on policy and practice, Springer: Dordrechdt, The Netherlands. Pp 1-14 http://link.springer.com/book/10.1007\%2F978-981-10-2275-3

Friedman, S. L., \& Boyle, D. E., (2008). Attachment in US children experiencing nonmaternal care in the early 1990s. Attachment and Human Development, 10(3), 225-261

Gallagher, T and Tait, C. (2018) Setting up the baby and toddler provision. In T. Gallagher and C. Arnold (Eds) Working with Children aged 0-3 and their Famiiies. The Pen Green Approach. pp 21-42. London and New York: Routledge.

Giles, L.C., Davies, M.J., Whitrow, M.J., Warin, M.J., \& Moore, V. (2011). Maternal depressive symptoms and child care during toddlerhood relate to child behavior at age 5 years. Pediatrics, 128 (1): e78-e84.

Goouch, K., \& Powell, S. (2017). Babyroom workers: care in practice. In E.J. White \& C. Dalli (eds.), Under Three Year Olds in Policy and Practice, pp. 143-157. New Zealand: Springer.

Gradovski, M., Odegaard, E., Mika, C., Rutanen, N., Sumsion, J. \& White, E.J. (2019). Becoming: The first 1000 days. Springer: Dordrechdt, in press.

Herba, C., Ernest Tremblay, R. E., Boivin, M., Liu, X., Mongeau, C., \& Seguin J.R.(2013). Maternal Depressive Symptoms and Children's Emotional Problems: Can Early Child Care Help Children of Depressed Mothers? JAMA Psychiatry 70(8):1-9 DOI:

10.1001/jamapsychiatry.2013.1361

Klette, T. \& Killen, K. (2018). Painful transitions: a study of 1-year-old toddlers' reactions to separation and reunion with their mothers after 1 month in childcare. Early Child Development and Care (1). https://doi.org/10.1080/03004430.2018.1424150

Kunda, Z., \& Sherman-Williams, B. (1993). Stereotypes and the construal of individuating information. Personality and Social. Psychology Bulletin, 19, 90-99.

Lee, L-C., Halpern, C. T., Hertz-Picciotto, I., Martin, S.. L. \& Suchindran, C. M. (2006). Child Care and Social Support Modify the Association between Maternal Depressive Symptoms and Early Childhood Behavior Problems: A US National Study. Journal of Epidemiology and Community Health, 60(4), 305-10.

Melhuish, E., Ereky-Stevens, K., Petrogiannis, K., Ariescu, A., Penderi, E., Rentzou, K., Tawell, A., Slot, P.,Broekhuizen, M., \& Leseman, P. (2015). A review of research on the effects of early childhood Education and Care (ECEC) upon child development. CARE project; Curriculum Quality Analysis and Impact Review of European Early Childhood Education and Care (ECEC). Available at http://ecec-care.org/resources/publications/ 
This is a peer-reviewed, accepted author manuscript of the following research article: Marwick, $H$., White, E. J., Rutanen, N., Souza Amorim, K., Herold, LKM., \& Karagiannidou, E. (Accepted/In press). Expectations and emotions concerning infant transitions to ECEC: international dialogues with parents and teachers. European Early Childhood Education Research Journal, 28(3).

Monk, H. \& Hall, H. (2017). New mothers transitioning to employment: Impact on infant feeding practices. In. L. Li, et al (Eds.). Studying babies and toddlers, International Perspectives on Early Childhood Education and Development 20, 63-80. Singapore: Springer.

OECD (2017). Starting Strong V: Transitions from Early Childhood Education and Care to Primary Education, Starting Strong, OECD Publishing, Paris.

https://doi.org/10.1787/9789264276253-en.

Pirskanen, H., Jokinen, K., Karhinen-Soppo. A., Notko, M., Lämsä, T., Otani, M., Meil, G., Romero-Balsas, P. \& Rogero-García, J. (2019). Children's emotions in educational settings: Teachers perceptions from Australia, China, Finland, Japan and Spain, Early Childhood Education Journal, 47, (4), 417-426.

Rossetti-Ferreira, M. C., Amorim, K. S., \& Silva, A. P. S. (2007). Network of meanings: A theoretical-methodological perspective for the investigation of human developmental processes. In J. Valsiner \& A. Rosa. (Eds.). Cambridge handbook of socio-cultural psychology, pp. 277-290. 1ed.Cambridge: Cambridge University Press.

Rutanen, N., Amorim, K. S., Marwick, H., \& White, J. (2018). Tensions and challenges concerning ethics on video research with young children: experiences from an international collaboration among seven countries. Journal of Education and Pedagogy, 3 (7), 0. doi:10.1186/s40990-018-0019-x

Traum, L. C., \& Moran, M. J. (2016). Parents' and teachers' reflections on the process of daily transitions in an infant and toddler laboratory school. Journal of Early Childhood Teacher Education, 37:4, 331-350, DOI:10.1080/10901027.2016.1241967

White, J., Hansen, K., Hawkes, K., Redder, B., Lord, W., \& Perks, N. (2018). Key teaching (primary caregiving?) practices during infant transitions to ECEC in Aotearoa New Zealand. The First Years: Ngā Tau Tuatahi. New Zealand Journal of Infant and Toddler Education. 20 (2), 5-13. 